\title{
The Folk Custom History of Ruanshe Wine Lane in Shaoxing
}

\author{
Ruoyu Li, Yihong Zheng \\ College of Architecture, Anhui Science and Technology University, Bengbu, Anhui, 233000, China
}

\begin{abstract}
:
Ruanshe used to be a well-known wine-making waterside village in Keqiao District, Shaoxing City, with a long history and profound cultural heritage. Based on the detailed introduction to the development of the local rice wine industry and the inheritors of wine shops, the paper explains the local characteristic "Wine Lane" developed in the rice wine culture, and elaborates on the unique architectural form of curtilage and stone pinned wall in Shaoxing, to help with the reconstruction of the ancient dwellings of Zhang's family from the Wine Lane, Moon on the Lake Expo Park, Bengbu City.
\end{abstract}

Keywords: Ruanshe, Wine country, Wine lane, Curtilage, Stone pinned wall.

\section{OVERVIEW OF RUANSHE}

The "Ancient Dwelling of Zhang's Family from the Wine Lane, Shaoxing" under reconstruction in the Moon on the Lake Ancient Dwelling Expo Park in Bengbu City, Anhui Province acquired the former ancient dwelling of Zhang Yuben, a descendant of the wine brand Shanyuantai Zhanghongji in Ruanshe, Shaoxing, Zhejiang.

According to legend, in Wei and Jin dynasties, Ruan Ji and Ruan Xian, both of whom were known as the famous "Seven Sages of the Bamboo Grove", lived in seclusion in Ruanshe, Shaoxing to escape the persecution of treacherous court officials. Later, they were regarded as the local guardian god for they were open-minded, generous and talented, and two temples were built to worship them; the temple in front was built to worship Ruan Xian and temple behind was built to worship Ruan Ji; later, a bridge was built near the temple behind, which was called Jixian Bridge. This place used to be called Ruan Li and Ruan Chuan; according to legend, Ruanshe referred in particular to the region where the two temples were located in the past, and later it became the collective name of the seven villages in Ruanshe Township, also called Ruanzhulinshe. "Two Ruans" are good at music and hard-drinking, so they were also regarded as the ancestor of Ruanshe's wine culture, which is the reason why Ruanshe got its 

name.

Ruanshe is located in the southwest of Keqiao District, Shaoxing City, including seven villages: Ruansan Village, Ruansi Village, Chabang Village, Zhongxiang Village, Xianfeng Village, Dongjiang Village, and Hulouwan, Xinfeng Village. The southern part of it belongs to the Western Kuaiji Mountain, from where Qiuhu River, Xiangli River, and Xingtang River originate and flow into the part of Jianhu Lake in Ruanshe. There is a well-known local proverb: "On the vast area of Ruanshe, there are three bays and eighteenth wharves, two temples and five ancestral halls, and seven nunneries". "Bay" refers to the confluence of rivers, which is a natural place for berthing. Bays are generally surrounded by large curtilages, such as Zhang's curtilage, Dafudi, Simadi, etc. "Wharf" refers to private wharves built by wealthy and influential local families to facilitate the transportation of goods by diverting water to their homes, which is named after the family's surname after completion, such as Chenjialou and Zhujialou [1].

\section{HISTORY OF THE WINE COUNTRY}

Ruanshe is a famous cradle for rice wine, which used to enjoy the reputation of Shaoxing's "Three Wine Countries" together with Dongpu and Hutang, constituting the "West Faction" among the rice wine producing areas, while the "East Faction" includes Doumen, Mashan, Sun Duan and other places. At present, Dongpu and Hutang are developing "Rice Wine Towns", to integrate the water country in Yangtze River Delta and the rice wine culture and restore to the former grandeur of the wine country. However, according to government planning, dwellings in Ruanshe were demolished during the urban village renewal project in Keqiao District, Shaoxing City in 2017, and the famous Ruanshe "Wine Lane" in history has permanently disappeared.

\subsection{Rice Wine}

As the predecessor of Shaoxing rice wine, "Shanyin Wine" had been well-known in the Wei, Jin, Southern and Northern Dynasties. There is an accurate record in Jin Lou Zi by Xiao Yi, Emperor Yuan of Liang: "When I was young, a silver cup was used to store Shanyin sweet wine in summer." In Tang and Song Dynasties, the imperial court set up wine institutions to supervise and urge the wine monopoly system, and more wine types emerged, among which "Nu Er Hong", "Zhuang Yuan Hong", and "Hua Diao Wine" were very famous.

The quality of Ruanshe rice wine is inseparable from the water of Jianhu Lake, which has 36 sources in Kuaiji and Shanyin Counties. The lake has three bends; the first bend is from the 

third bend is from Lizhu to Dongpu. These three bends have humid climate and fertile soil, ensuring high water quality. During the reign of Daoguang in Qing Dynasty, Liang Zhangju wrote in Lang Ji Xu Tan: "Today, Shaoxing wine sells well all over the country, and it can be called the authentic wine", "Perhaps the water Shanyin and Kuaiji is the most suitable for making wine, incomparable by water from any other places. Other places all use the same method as that in Shaoxing to make wine, but the water is different, so the taste is far worse." It clearly shows that the water quality affects the taste of rice wine, and the taste of rice wine brewed from water of Jianhu Lake is different from that in other places [2].

\subsection{The Wine Shops are Famous all over the Country}

Many well-known wine shops were founded in Ruanshe, especially the traditional rice wine brands that flourished during the reign of Qianlong in Qing Dynasty, such as Zhangdongming, Shanyuantai, Gaochangxing, were well-known in Beijing and Shanghai. Among them, Zhangdongming wine shop was the largest; when the five ports were open in the 22nd year of Daoguang's reign (1842), its annual brewing capacity reached more than 6000 cylinders, more than 300 kilograms / cylinder, and products were exported to Southeast Asia. In 1848, Zhangdongming wine brand entered Shanghai and set up two branches in the north and south; later it entered Tianjin and used "Quancheng Mingji" as the trade name, which only operated wholesale business and also served as a sales point in the north, direct selling to the three northeastern provinces, so it was also called "Jingzhuang". At that time, Shaoxing wine brands had an industry regulation of packaging in different weights according to the places of sale: "Small Jingzhuang" referred to package with 5kg per jar, "Big Jingzhuang" referred to package with $25 \mathrm{~kg}$ per jar, "Jingzhuang" was sold in the north only, "Shenzhuang" was sold to Jiangsu, Zhejiang and Shanghai, and "Jianzhuang" was sold to Guangdong, Fujian and Guangxi. With the expansion and growth of the business in the north, it started a long-term cooperation with Beijing Tongrentang Pharmacy; for this purpose, it specially made a medicinal wine called "Shibaliutong", which was of high quality and must be stored for three years before it can be delivered. Later, the cooperation naturally stopped during the warlord dogfight in the Republic of China. At the same time, the flourishing population of Zhang Dongming's family expanded and inherited the business of the wine shop, developing many branches, such as Zhangdongming Junji, Zhangdongming Xinji, Zhangdongming Zhengji, also known as "Three-Dongming"; among them, Junji was the largest, which later derived many branches, such as Jieji, Fangji, etc., all of which were well-known local rice wine brands. Zhangdongming Wine Shop strictly controlled quality, and used top-quality sticky rice from Jiangsu as raw materials, and the water from Shimentang in the upper reaches of Jianhu Lake, which is why the wine shop has lasted for seven generations and continues up to now [3]. 
The products of current famous rice wine brand Kuaijishan Shaoxing Wine Co., Ltd. are also from Ruanshe. In the eighth year of Emperor Qianlong's reign in Qing Dynasty (1743), Zhou Jiamu founded Yunji Wine Shop in Dongpu, and his descendants continued the business; in 1951, it was acquired by the local government and became a local state-owned Yunji Winery. The original winery in Dongpu was too small for the production capacity and sales volume of rice wine that increased year after year, so it moved to Hutang the following year. In 1954, it acquired other brands' factories in Xinfeng Village, Ruanshe and the opposite bank of Dongjiang River; at this time, Yunji Distillery had three factories, Hutang, Dongjiang Rice Wine and Xinfeng Village Liquor. In 1956, it was rated as a "Shaoxing Wine Sorting, Summary and Improvement" project and included in the National Twelve-Year Science and Technology Development Plan. In the same year, the central government invested and acquired land to expand factories and warehouses in Dongiiang, and rebuild roads and other projects. In 1957, the state again allocated special funds to expand the factory and built large storage and fermentation workshops. In 1959, in order to strengthen the management of local wineries, Shaoxing government merged the five wineries, including Shaoxing Winery, Yunji Winery, public-private joint Shenyonghe Winery, Keqiao Winery, and Dongpu Winery, to establish Shaoxing Jianhu Changchun Winery, and the site of former Yunji Winery became the second workshop of the new winery. In 1961, due to natural disasters, grain output dropped sharply, and it was downsized to three wineries of Shaoxing, Yunji, and Shenyonghe. During this period, the winery went through transfer and reorganization, and changed its name several times, and it was changed to Kuaijishan Shaoxing Wine Co., Ltd. in 2007 and became a joint-stock company.

\subsection{Stories about the Wine Lane}

Ruanshe was the place gathering Shaoxing wine shops in the 1930s. During the Republic of China, the sales volume of rice wine surpassed Dongpu and Hutang, ranking at the top. Many wealthy and influential families made their fortunes by operating wine workshops. At that time, the rice wine was sold to Beijing and Tianjin in the north, and Guangdong and Fujian in the south, and was exported to Southeast Asia via Shanghai Port. During the period of the Republic of China, 14 of the 22 rice wine enterprises in Shanghai were from Ruanshe; after returning from Shanghai, these bosses enriched their horizons and brought back advanced ideas, and Ruanshe was once known as "Little Shanghai". "Making money outside, and buying land and building a house in hometown" is the traditional family concept of Shaoxing people. With more houses built, lanes are formed between houses. The "Wine Lane" in Ruanshechi Bay is the mark left by the heyday of Shaoxing rice wine. 
Formerly known as "Ditch Lane", "Wine Lane" was originally located on the east side of Chiwan, Ruansan Village, as a drainage ditch for surrounding farmland; after the houses on both sides were built, bluestone slabs were laid on it to form a sidewalk. The lane is about 2 meters wide and about 100 meters long. On the south side is a three-slab stone pinned wall, which is the dwelling of Shanyuantai's master; on the north side is a two-slab stone pinned wall, which was the courtyard of Zhangdongming Wine Shop at beginning. In the past, there was a strict hierarchical system for building stone pinned walls, in which the amount of boards did not depend on the wealth level of the house owner, but on the social status; only official dwellings could use stones above three slabs, while two-slab stones were for ordinary families. According to the folk legends in Ruanshe, the height of two-slab stone pinned wall in the lane exceeds that of three-slab stone pinned wall, because the house owner, who was a merchant, wanted to demonstrate the family property but did not dare to go beyond the traditional hierarchical system. According to verification of historical sources, this theory is nonsense.

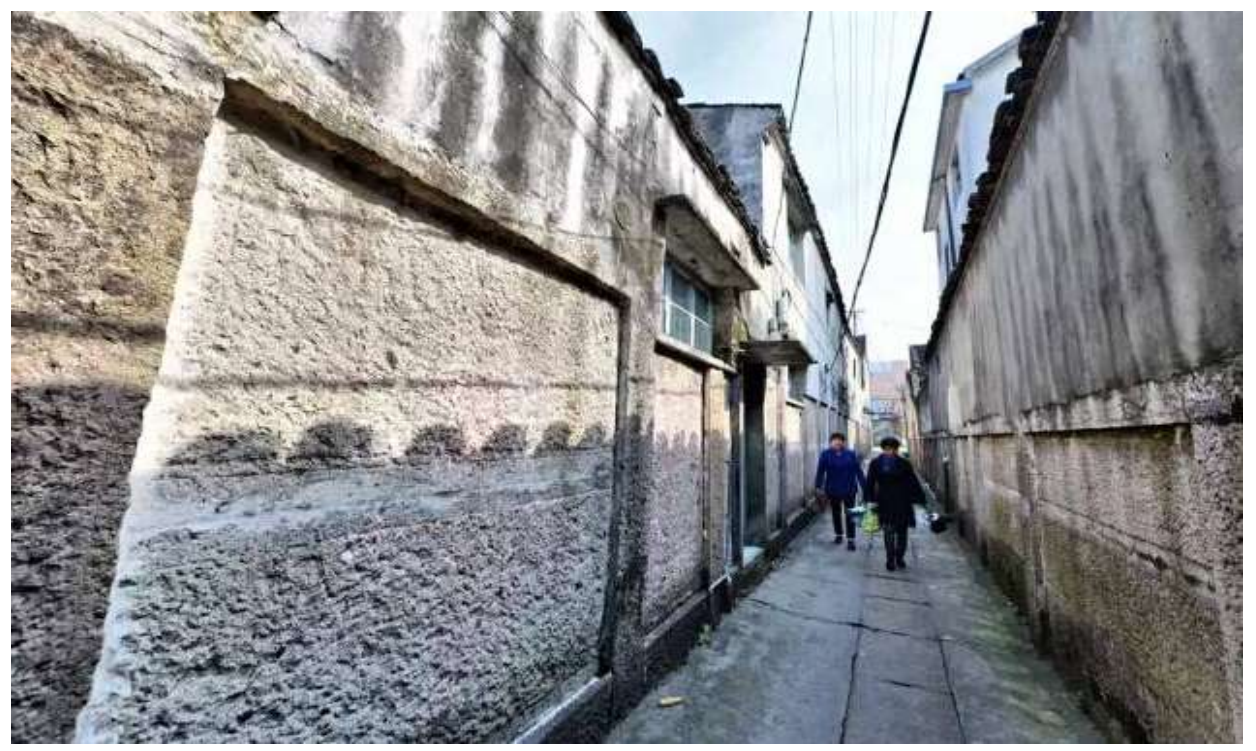

Fig 1. Wine lane

The owners of Zhangdongming and Shanyuantai Wine Shops were both descendants of Zhang Zhaoliang. Zhang Zhaoliang, also known as Qixian, was the founder of Zhang's Brewing, the fifteenth generation of Zhang's family in Ruanshe. His father died when he was young, and his family was very poor, but he was knowledgeable and engaged in agricultural activities when he was an adult. Zhang's Family Genealogy of Ruanshe, Shanyin says, "He accumulates surplus funds to make wine, and the brewing technique is famous in the county". Since then, he gave up farming and went into business, and his family started to flourish. Zhang Zhaoliang had three sons, Zhang Menggeng (as known as Dongming), Zhang Mengshu (as 

known as Danyi), and Zhang Mengling (as known as Weishan) from old to young. In the early days, Zhang Dongming and his brothers inherited their father's business and worked together to run the wine shop and build the brand "Zhangdongming". As the saying goes, when trees grow up, they start to ramify, and when people grow up, they start to divide up family property and live apart, Zhang Weishan's second son, Zhang Wenhong, slowly signed Zhanghongji on the wine shop's receipts, and then started his own business and gradually developed into Shanyuantai Zhanghongji [4].

The owners on the north and south sides of the Wine Lane are brothers, both descendants of Zhang Wenhong. In 1931, the brothers divided up family property; the elder brother Zhang Chunan had more children, and got the ancestral home in the north; the courtyard in the south used to be Simadi curtilage, which was bought from the house of a declining official's family and was given to the younger brother Zhang Rongsheng. Later, Zhang Chunan no longer cared about the business of the wine shop and was addicted to Confucianism. The business of Shanyuantai Wine Shop was completely handed over to Zhang Rongsheng. Later, the business ran smoothly, and the wine production affected daily life, so he moved the wine manufacturing and processing site to the right bank of Bailuojing Bay; later, no more wine was produced in the Wine Lane, and it was only used as a dwelling for the descendants of Zhang's family.

As time flies, in the Wine Lane between the two-slab and three-slab stone pinned walls, the bluestone slabs are polished day by day by the rice wine transporter, who shouted slogans while going there and back in the lane full of bouquet, making Ruanshe's "Wine Lane" famous.

Zhang Yuben, who is in his old age, is the heir of Zhanghongji of Shaoxing Shanyuantai in Zhejiang. His father was Zhang Rongsheng, who was known as "Store Owner Rongsheng" in Ruansan Village. Zhang Rongsheng was well-known for wine brewing, who not only controlled production, but also focused on operation and sales. He opened Shanyuantai Shaoxing wine store by Shanghai ball throwing field. There were more than 100 jars of wine collected in the wine shop during the Cultural Revolution. He was philanthropic and helpful, and named his two sons Yushan and Yuben, meaning kindness and devoir. Because of his concern for charity and public undertakings, he was loved by all the residents of in Ruanshe at that time, and the government gave him the title of "Enlightened Gentleman" after liberation.

\section{RUANSHE DWELLING}

\subsection{Stone Pinned Wall}

The dwellings in Ruanshe have the typical architectural style of water country in Yangtze 
River Delta and are built along rivers. The stone terraces built by rivers are neat and clean, solid and practical. The stone paths on stone terraces are level and smooth, providing convenience for residents' travel. In the stone buildings, the stone pinned wall is quite unique, which uses smooth bluestone slabs as the wall base of houses, and use slotted stone pillars at both ends. The bluestone slabs are inserted into the grooves and pinned, so it is called stone "pinned" wall. The wall is usually about 1.5 to 2 meters high, and bricks are placed on the wall. The stone pinned wall is durable, moisture-proof and safe. Ruanshe is surrounded by water on four sides, and the ground is damp. The mud bricks are easy to soften when the water accumulates, while the stone pinned wall is very solid. As a result, the stone pinned wall in the area is tens of meters long, which is very spectacular at first glance. It not only has the beauty of regularity and neatness, and also has a sense of plentiful strength, so it is a unique scene in Ruanshe Village. Shaoxing is the first to excavate stone pits in Zhejiang Province, the stone materials are more sufficient than other building materials, so bricks were abandoned and stone pinned walls are used. Therefore, this form of stone pinned wall as a base wall only exists in Shaoxing, and is not seen in other ancient villages in the Yangtze River Delta.

Although the stone pinned wall is unique in the global architecture, it has never attracted the attention of the construction industry. Not only has no one mentioned it, but it has no standard name so far; some call it "stone (Shi) pinned (Xiao) wall (Qiang)", some call it "Shi Xiao Qiang" according to the phrase in the Analects of Confucius, and some call it "Shi Xiao Yang" because "Qiang" sounds like "Yang" in Shaoxing dialect. However, "Yang" is not used in the local dialect of Shaoxing, but it often appears in words in dialects of southern Zhejiang such as Wenzhou and Lishui. The stone pinned wall can be described as a unique case in the country; unfortunately, this unique architectural form will come to an end without an official uniform naming.

\subsection{Shaoxing Curtilage}

Most of the houses in Ruanshe are two-story buildings, with doors and windows facing south, which ensures plenty of sunlight and avoids the north wind on the plain; they are warm in winter and cool in summer, and can be called typical water country dwellings on the plain.

The house form of curtilage is unique to Shaoxing area. It has long been a dedicated name for the dwellings of high-ranking officials, and later it refers to independent courtyards. Usually it can be divided into three types: the first is an independent hall, the second is connected hall and wing-room, and the third is a quadrangle courtyard without independent halls. Curtilage has white walls and black tiles, stone steps and door frames; inside the curtilage is usually three to nine entrances. The gate and the etiquette gate are the first entrance, and there is a patio or 
Article History: Received: 10 May 2021 Revised: 20 June 2021 Accepted: 18 July 2021 Publication: 31 August 2021 open hall in the middle; the hall is the second entrance; there are usually at least five entrances, including the principal room and the wing room, with a garden behind. The curtilage is plain and rigorous, simple in structure, modest, and masculine. Stone windows are often used in curtilage. The stone carvings on the windows are exquisite, with vivid historical figures, flowers, birds and beasts, and are artworks in stone culture. There are hundreds of curtilages in the village, many of which are built near rivers to facilitate the passage of waterways, especially in Dongjiang Village, many curtilages are built almost in parallel. Curtilages mostly use the shape of Shikumen; wealthy families generally have two black lacquered fir gates, and official or scholarly families have six or eight bamboo silk gates [5].

The stone pinned walls, Shikumen, and bluestone slabs in Ruanshe, Shaoxing are all exquisite, but now there are very few left. Many of curtilages and Shikumen have been demolished, and some are planned to be moved to the ancient town of Keqiao. Only Zhu's curtilage, front and rear temple, Fuqian Temple, Jixian Bridge and Shuige Bridge.

\section{CONCLUSION}

After investigation and research on the repaired building warehouse and the repairing platform of craftsmen, the stone-pinned walls and stone slabs of the old house of Zhang's former dwelling and the pine wood components of the house were all rescued and preserved before the renovation and demolition of the old city of Ruanshe. Some of the brewing utensils preserved by Zhang Yuben and his descendants are completely collected; most of the utensils are made of wood, bamboo and ceramics, and a small amount of them are made of tin; there are mainly clay jars, wine jars, tile jar covers, rice sieves, steaming barrels, bottom barrels, bamboo mats, wooden rakes, wooden shovels, buckets, funnels, wooden squeezers, frying pots, pots, etc. There are also some furniture such as storage cabinets, tables, chairs and benches. Zhang Yuben and his family were invited to witness at the foundation stone laying ceremony of the "Ancient Dwelling of Zhang's Family from the Wine Lane, Shaoxing" in the park in August 2017. The old and profound Ruanshe Wine Lane is being built around Zhang's former residence, and the rice wine culture in Shaoxing, Zhejiang Province has also been moved to Bengbu City, Anhui Province, forming a unique cultural landscape displaying Chinese Huadiao Wine.

\section{ACKNOWLEDGEMENTS}

This research was supported by Think Tank Construction and Social Science Planning Project of Bengbu City (BB20B057), Research on the Culture and Artistic Value of Ancient Dwellings of Moon on the Lake; National Social Science Fund Project, (16BF073) Research on Stone Inscriptions of the Emperor's Mausoleum in Ming Dynasty. 


\section{REFERENCES}

[1] Qiu Zhirong (2018) Research on the history of the ancient village Ruanshe in Shaoxing. Journal of Zhejiang University of Water Resources and Electric Power 30(05):1-11

[2] Lin Wenbiao (2001) Analysis of the Reasons Why Shaoxing has Become the "Hometown of Rice Wine" in China. Journal of Shaoxing University (Philosophy and Social Sciences Edition) (01):12-16

[3] Qian Maozhu (2017) Four Notes of Ruanshe. Jianhu, China Volume Iv. Beijing: China Literature and History Publishing House: 248-260

[4] Zhou Yan'er (2019) Interpretation of Cai Yuanpei's Lost script Zhang Zhengqing Biography. Zhejiang Archives (09):54-55

[5] Fu Zhenzhao (1999) Shaoxing County Annals, Volume 2: Economics and Politics Beijing: Zhonghua Book Company 